\title{
2. Summary of Reported Isolations of Bacteria, 1985
}

\section{$\underline{\text { Overview }}$}

The total number of bacterial isolation reports (involving imported cases) in 1985 (Fig. 5) was as follows: 18,149 at PHI/HC, 77,432 at GCI, 1,205 at IDH, and 1,929 at quarantine stations. The respective figures represent $102 \%, 114 \%, 101 \%$ and $118 \%$ of the reported number in the year before. The numbers therefore, increased at GCI and quarantine stations compared with the preceding year.

Isolations from overseas travelers, namely imported cases, numbered 2,355 at $\mathrm{PHI} / \mathrm{HC}$ (13.0\% of total isolations from the respective institution), 56 at GCI $(0.07 \%), 495$ at $\operatorname{IDH}(41.1 \%)$, and 1,929 at quarantine stations $(100 \%)$. The proportion at each institution was nearly the same as the year before.

For $\mathrm{PHI} / \mathrm{HC}$, the bacterial pathogen reported most frequently was Salmonella, accounting for $23.1 \%$ of all PHI/HC reports in 1985 (23.8\% in 1984). Other bacterial pathogens found were as follows: Streptococcus accounting for $18.5 \%$ (20.9\% in 1984), Vibrio parahaemolyticus $16.1 \%$ (12.4\%), Campylobacter jejuni/coli $15.5 \%(13.5 \%)$ and Escherichia coli $8.6 \%$ (9.9\%). The order of frequency was the same as the year before except $V$. parahaemolyticus and $C$. jejuni/coli exchanged positions. The breakdown of cases of isolations from overseas travelers, was: $33.0 \%$ for $E$. coli (32.3\% in 1984), $23.2 \%$ for Salmonella (24.4\%), 14.4\% for $V$. parahaemolyticus (13.7\%), 9.4\% for Shigella (9.9\%), $7.6 \%$ for Plesiomonas shigelloides (5.4\%), 5.4\% for C. jejuni /coli (5.2\%) and 3.5\% for Vibrio cholerae 0-1 and non 0-1 (6.0\%). The types of major bacteria remained unchanged (Fig. 5-1).

$\mathrm{GCI}$, in contrast to $\mathrm{PHI} / \mathrm{HC}$, reported more isolations from the respiratory tract than from the intestinal tract. The percentages of reports for these respiratory pathogens in 1985 were $23.8 \%$ for Streptococcus (22.7\% in 1984), $22.1 \%$ for Haemophilus influenzae (22.3\%), 19.4\% for Klebsiella pneumoniae (20.0\%) and $12.1 \%$ for Streptococcus pneumoniae (13.4\%). As for bacteria causing infectious diseases of the gastro-intestinal tract, the percent breakdowns for all reports from the institute were $8.6 \%$ for C. jejuni /coli (7.9\% in 1984), $2.9 \%$ for $E$. coli (3.1\%) and $2.6 \%$ for Salmonella (2.6\%). Fifty-six imported cases were reported, the majority of which were intestinal pathogens. Of these, 29 (51.8\%) were Shigella (Fig. 5-2).

All isolations from IDH inpatients with suspected legally designated notifiable infectious diseases caused by enteric pathogens were reported. Shigella was the most frequently reported pathogen and accounted for $37.9 \%$ of the total isolations at IDH in 1985. Next most frequent pathogen was Salmonella (23.0\%), followed by $C$. jejuni/coli (10.8\%). In addition, Entamoeba histolytica was reported 
Vol. 39, Suppl.
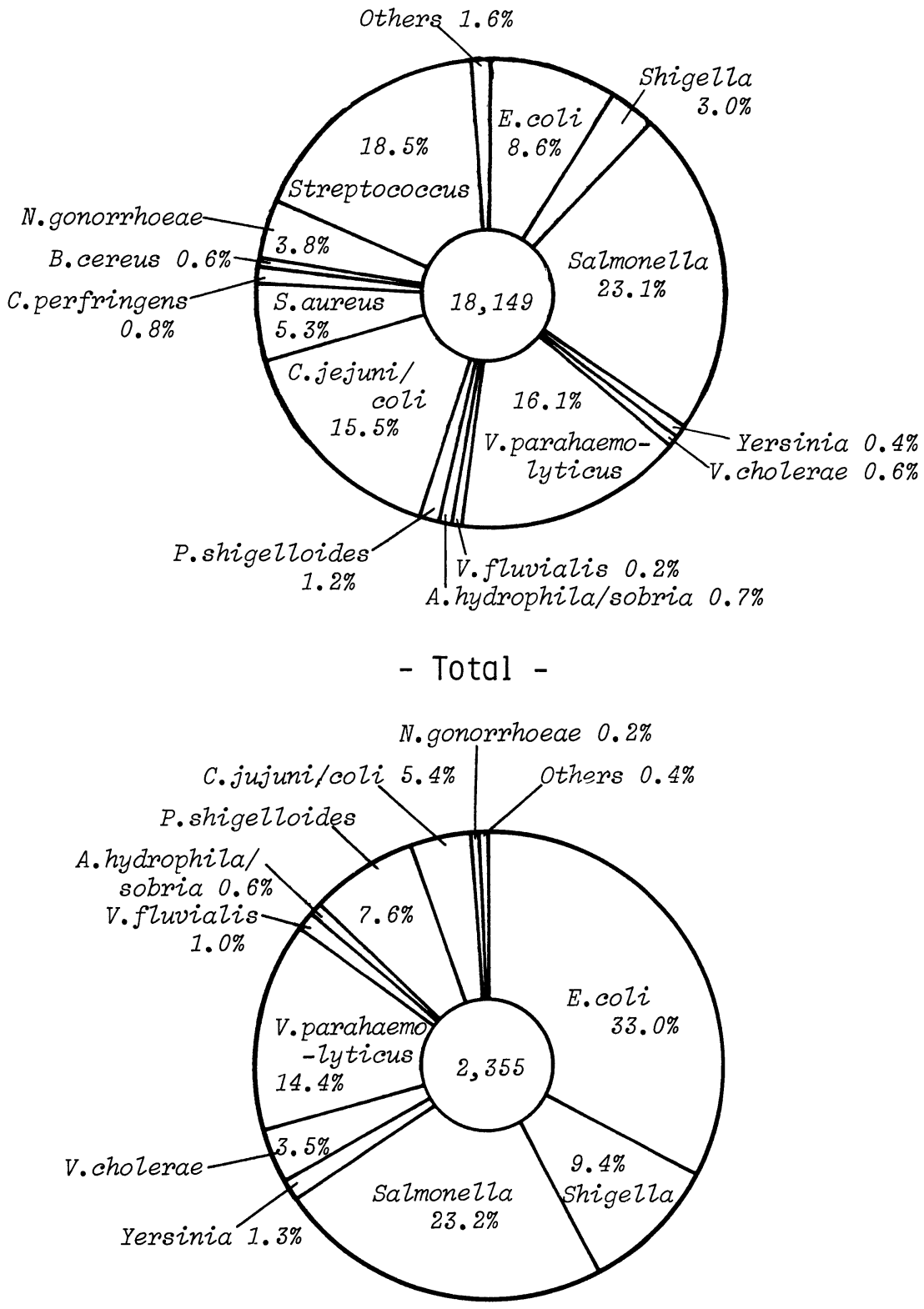

- Imported cases -

Fig. 5. Reported isolations of bacteria from humans, 1985

5-1. Isolations by prefectural and municipal public health institutes and health centers 

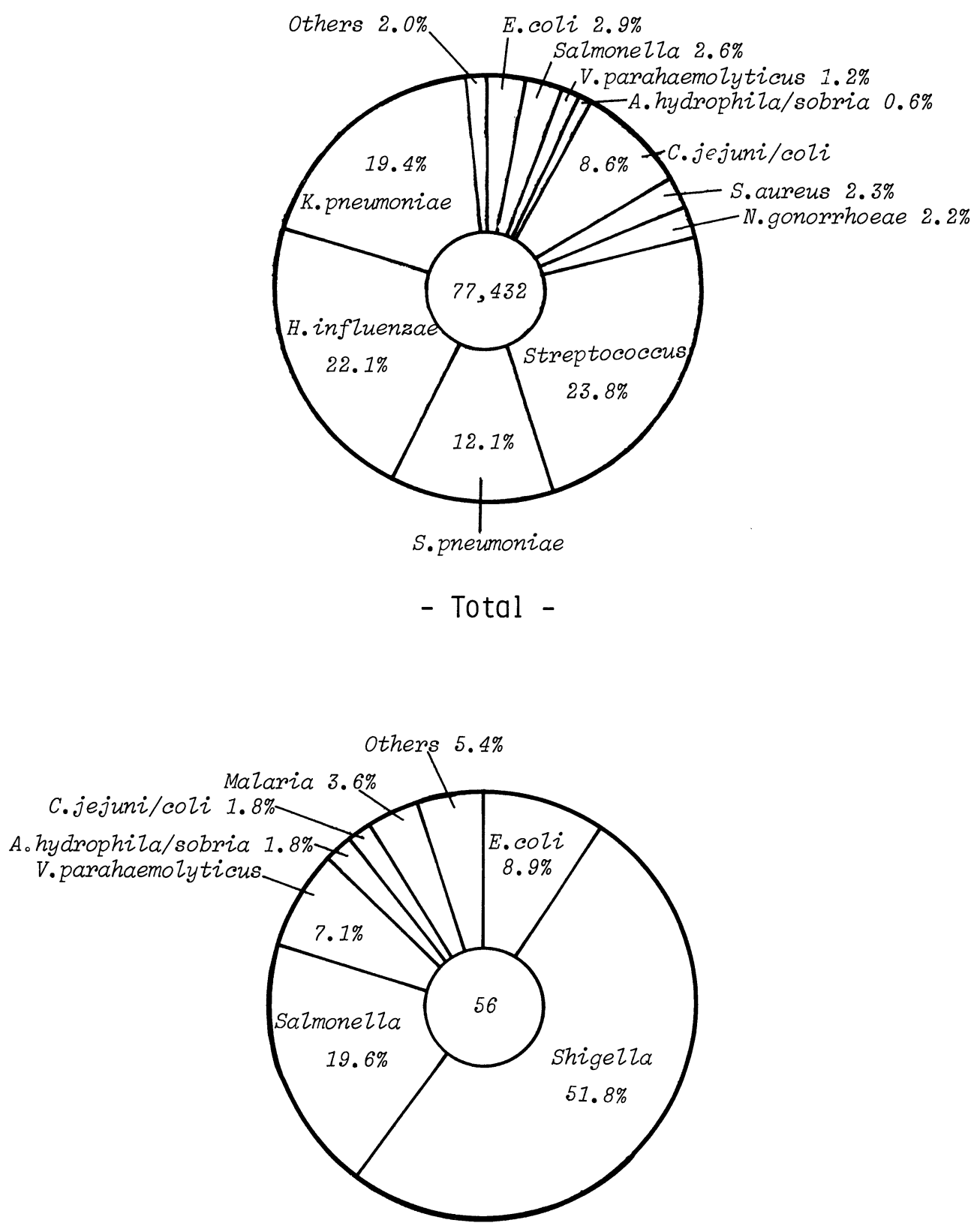

- Imported cases -

5-2. Isolations by general clinical institutions 
Vol. 39, SuppI.
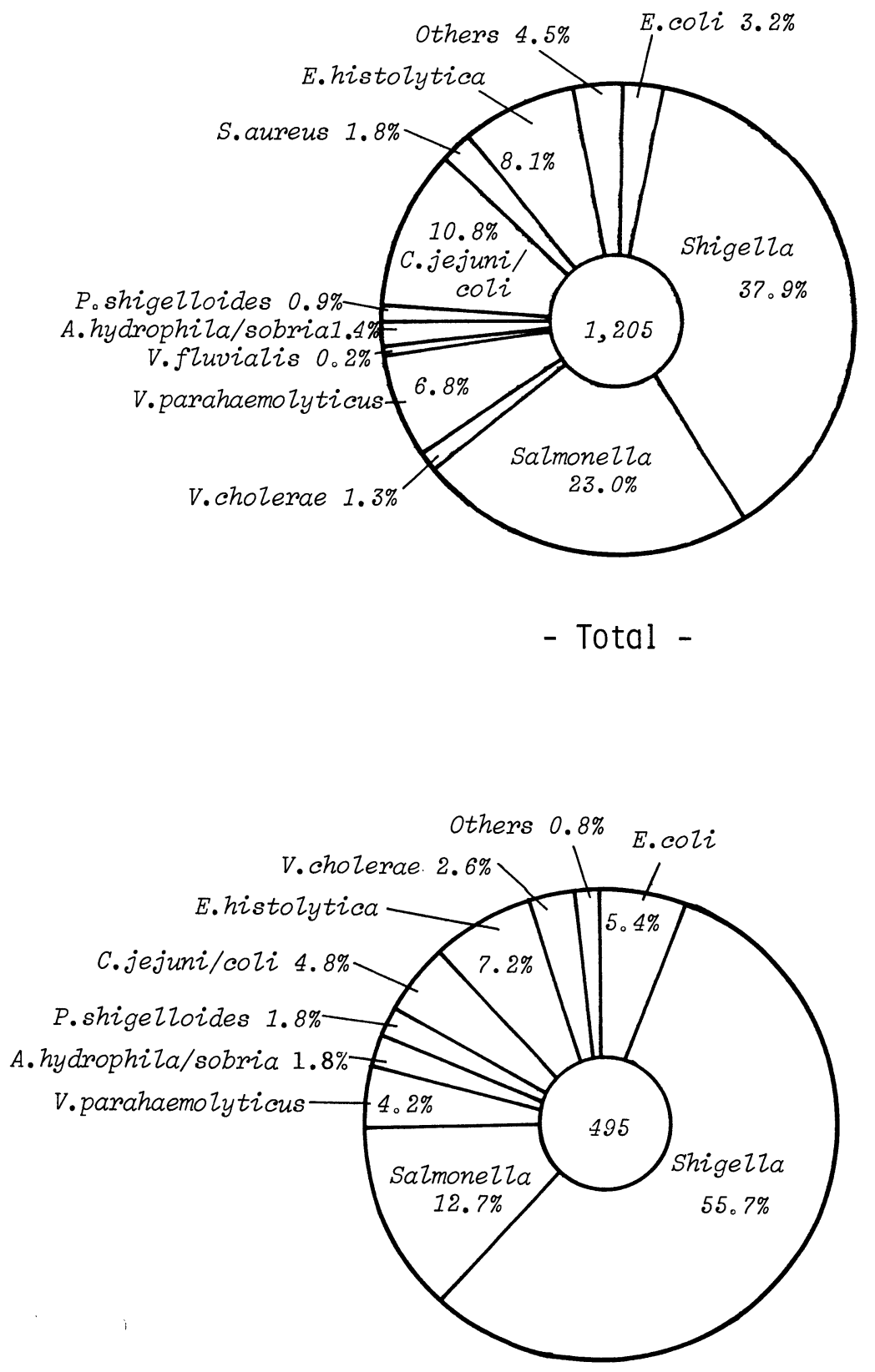

- Imported cases -

5-3. Isolations by infectious diseases hospitals 


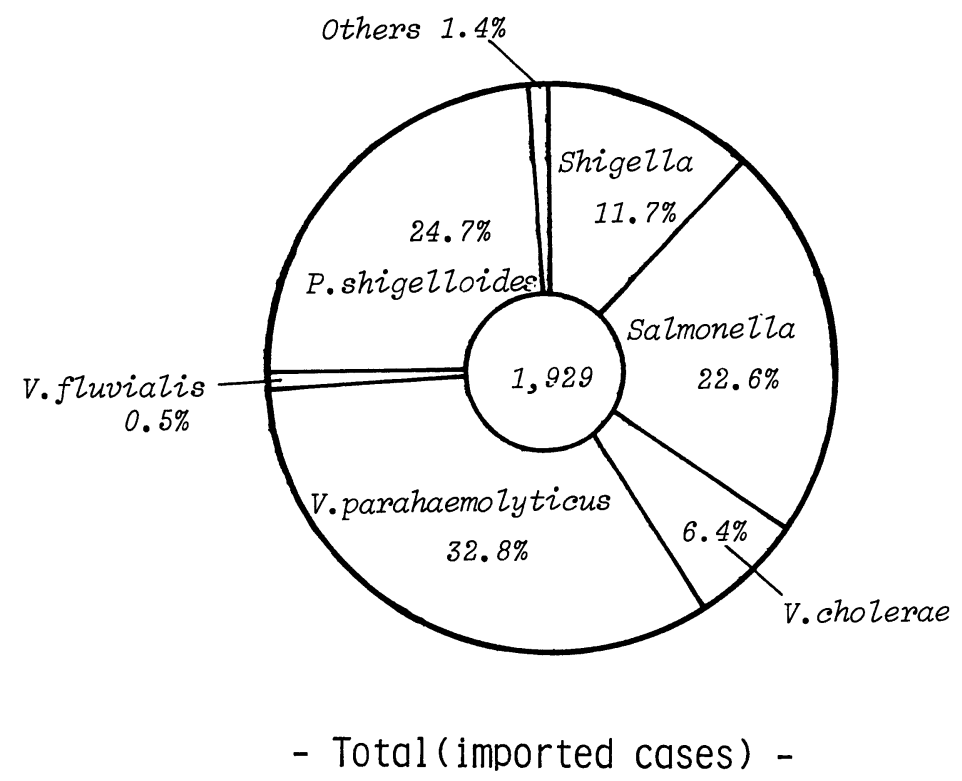

5-4. Isolations by quarantine stations

in $8.1 \%$. The proportion of Shigella increased to $55.7 \%$ among isolations from overseas travelers (Fig. 5-3).

All reports from quarantine stations were enteric pathogens isolated from overseas travelers. The most frequent pathogens isolated in 1985 were $V$. parahaemolyticus (32.8\%), followed by $P$. shigelloides (24.7\%), Salmonella (22.6\%), Shigella (11.7\%) and V. cholerae 0-1 and non 0-1 (6.4\%). The proportions of $V$. parahaemolyticus and $P$. shigelloides were high when compared with those at other institutions. There were only a few isolations of enteropathogenic $E$. coli because the detections of these bacteria are not performed routinely (Fig. 5-4). 
Vol. 39, Suppl.

\section{Shigella}

The annual number of Shigella isolations reported by PHI/HC was 540 in 1985. The reported number of Shigella ranged between 500 600 in 1979, 1980, and 1982. However, the number rose to 815 in 1981, and was 1,180 in 1983, more than twice as many as the expected annual incidence. Outbreaks in 1985 have remained at the usual annual level as in 1984 (Fig. 6-1). Of the total Shigella findings, there were $336 \mathrm{~S}$. sonnei (62.2\%), $164 \mathrm{~S}$. flexneri (30.4\%), $30 \mathrm{~S}$. boydii (5.6\%), and $10 S$. dysenteriae (1.9\%). The number of imported cases of Shigella in 1985 was $222(41.1 \%)$. These cases accounted for $34.8 \%$ of $S$. sonnei, $45.1 \%$ of $S$. flexneri, $76.7 \%$ of $S$. boydii and $80 \%$ of $S$. dysenteriae. Of the imported cases, percent breakdowns of each group were $52.7 \%$ for $S$. sonnei, $33.3 \%$ for $S$. flexneri, $10.4 \%$ for S. boydii and 3.6\% for S. dysenteriae. Monthly isolations of Shigella in total from 1980 to 1985 are shown in Fig. 6-2, and the number of isolations of $S$. flexneri and S. sonnei are shown in Fig. 6-3.

At IDH, 457 detections of Shigella were reported in 1985. This number is almost the same as the previous year's 436 detections (Fig. 6-1). Two hundred seventy six imported cases were reported amounting to $60.4 \%$ of the total. Among these, $59.1 \%$ were $S$. sonnei, $31.5 \%$ were $S$. flexneri, $6.5 \%$ were $S$. boydii and $2.9 \%$ were $S$. dysenteriae. Compared with the reports from $\mathrm{PHI} / \mathrm{HC}$, the proportion of $S$. sonnei was slightly higher.

At quarantine stations, 226 detections were reported, of which $S$. sonnei, $S$. flexneri, S. boydii and S. dysenteriae represented 50.0\%, 35.4\%, 9.3\% and 5.3\%, respectively. Those rates were similar to those of imported cases reported from $\mathrm{PHI} / \mathrm{HC}$.

\section{$\underline{\text { Salmonella }}$}

$\mathrm{PHI} / \mathrm{HC}$ reported a total of 4,194 isolations of Salmonella from humans involving $S$. typhi and $S$. paratyphi. This was $99 \%$ of the previous year's total (4,237). Among these isolations, there were 546 imported cases which were $13.0 \%$ of the total. Reported findings by month rise to a broad peak in the summer, centered around August-September, on a yearly basis (Fig. 7). The main reason for the peak is the high frequency of outbreaks of food poisoning during this season. Apart from that, another important factor which increased the reported number is that results of the periodic fecal examinations for food handlers are mainly submitted in that season. Findings of Salmonella reported by IDH are also highest in July-September. 


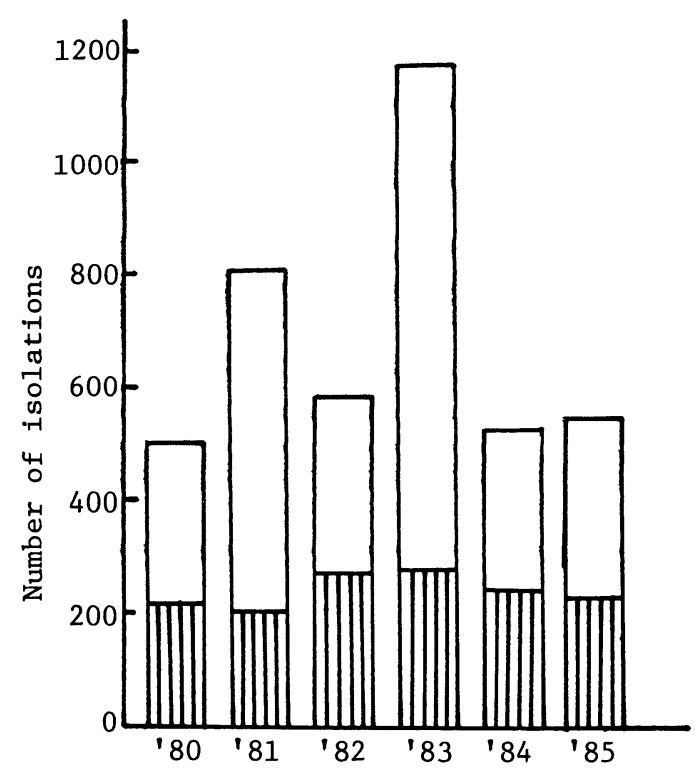

- Prefectural and municipal public health institutes and health centers -

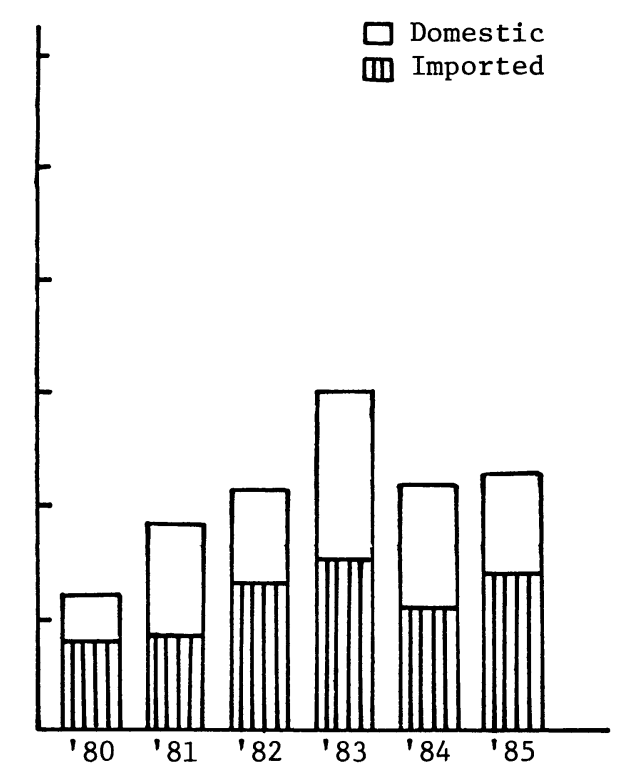

- Infectious diseases hospitals -

Fig. 6. Reported isolations of Shigella from humans, 1980-1985

6-1. Isolations by prefectural and municipal public health institutes and infectious diseases hospitals, by year

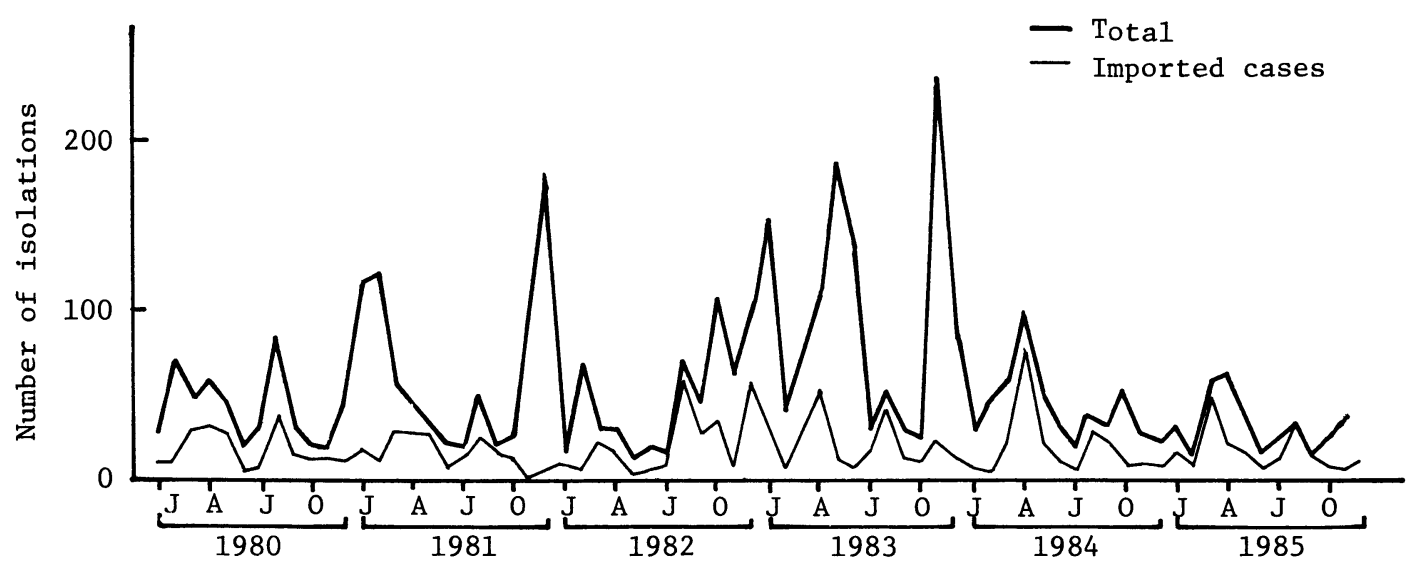

6-2. Isolations by prefectural and municipal public health institutes and health centers, by month 
Vol. 39, Suppl.
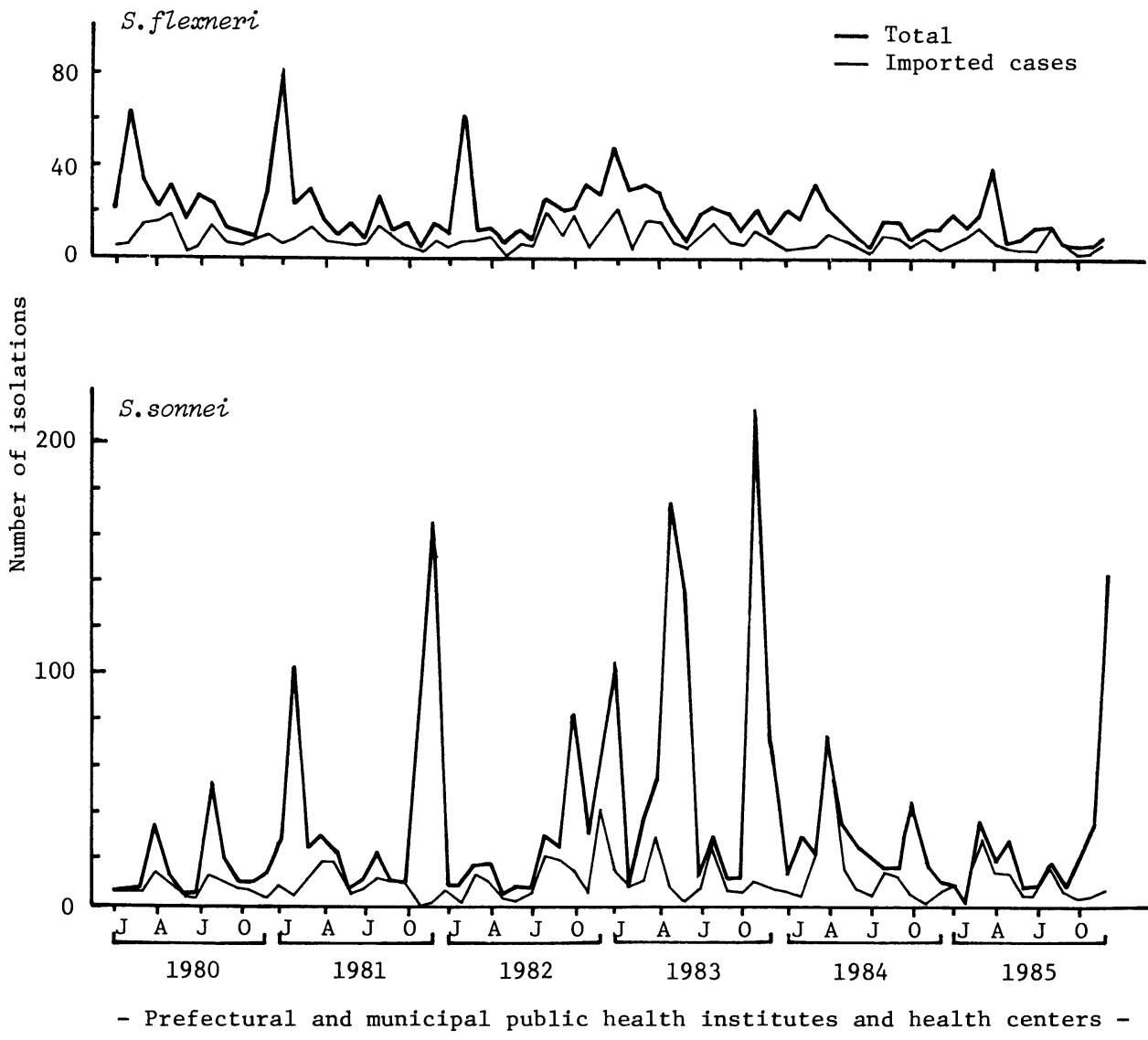

6-3. Isolation of S. flexneri and S. sonnet, by month

In general, for all reports, the most frequently isolated Salmonella group was group $\mathrm{O} 4$ (B) (including $S$. paratyphi B) (Fig. 8). The group O4 (B) frequencies for the respective institutions were: $34.5 \%$ at $\mathrm{PHI} / \mathrm{HC}$, and $50.5 \%$ at $\mathrm{IDH}$. For group $\mathrm{O} 4$ (B), the number of imported cases for $\mathrm{PHI} / \mathrm{HC}$ and quarantine stations were $22.9 \%$ and $24.4 \%$, respectively. The next most frequent isolation were group 07 (C1) and then group 08 (C2-C3). Imported cases, however, demonstrated a relatively higher frequency of group O3, 10 (E1) and O1, 3, 19 (E4); frequencies of these two groups of all imported Salmonella were $25.5 \%$ at $\mathrm{PHI} / \mathrm{HC}$ and $24.1 \%$ at quarantine stations. In contrast, these Salmonella represented only $3.8 \%$ of domestic Salmonella detections reported from PHI/HC.

$-26-$ 


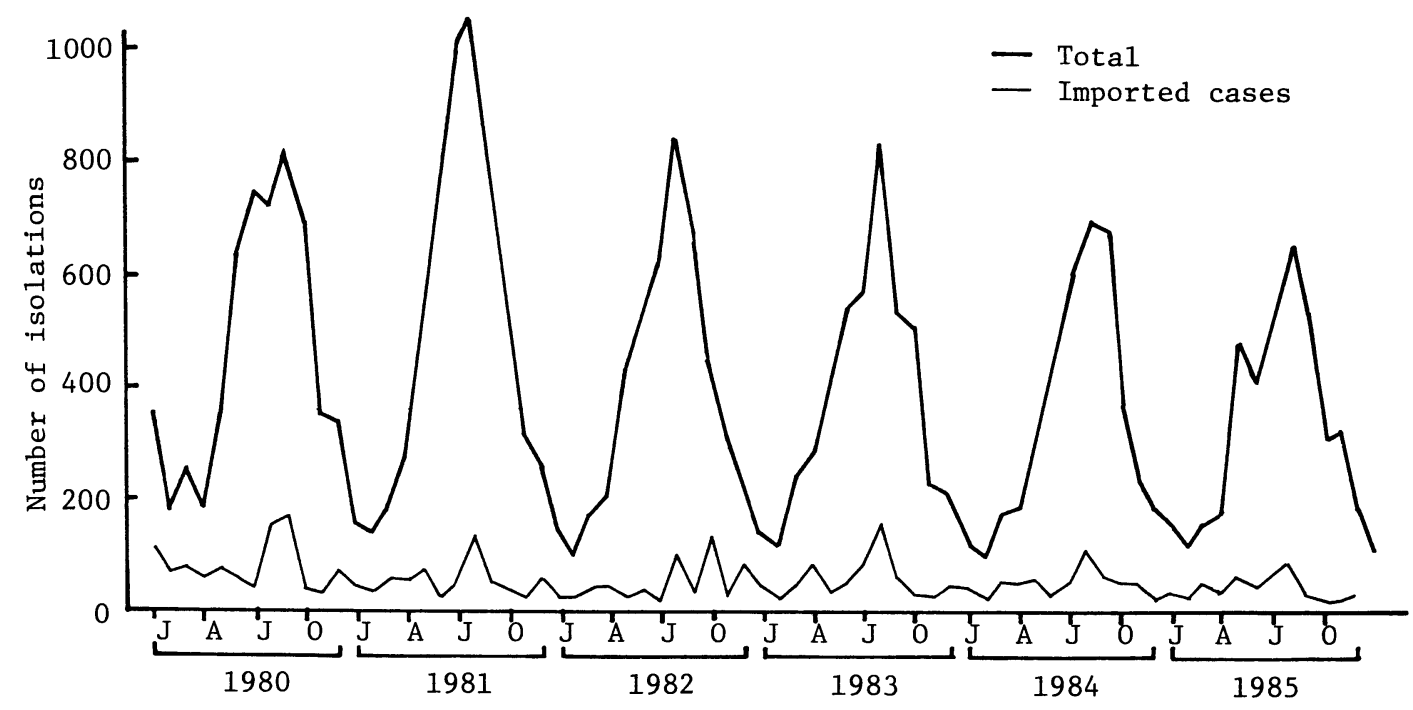

Fig. 7. Reported isolations of Salmonella other than S. typhi and S. paratyphi $A$ from humans by prefectural and municipal public health institutes and health centers, by month, 1980-1985

Among the Salmonella derived from humans, that was investigated at PHI/HC, serovars were reported for 4,172 strains. For all Salmonella serovars tested, 15 comprised the majority and represented $69.7 \%$. Among them, $768 \mathrm{~S}$. typhimurium represented the overwhelming majority $(18.4 \%)$ of all the serovar isolations, followed by $387 \mathrm{~S}$. litchfield (9.3\%), $267 \mathrm{~S}$. enteritidis (6.4\%), $254 \mathrm{~S}$. paratyphi B (6.1\%), and $215 \mathrm{~S}$. infantis (5.2\%) (Fig. 8-3). These serovar frequencies are consistent with previous trends. Exceptionally, S. itami, which were rare serovars in previous years were increased to as many as 95 isolations. However, the reports were all from a common outbreak in Ishikawa prefecture.

Concerning the nomenclature of the Salmonella O serologic group, the Salmonella Subcommittee of the International Enteric Bacterial Committee has determined that the previous Kauffmann-White Scheme should be changed. The change was recommended and finalized December 1984. Under the new taxonomic system, some serovars were deleted and some were combined. The reason for this change is that the number of Salmonella serovars exceeded 1,600, and some of the $\mathrm{O}$ antigen is transmitted by phage, making the $\mathrm{O}$ antigen expression unstable. For the present report, although Salmonella monthly reports (Table I, II) are tabulated according to the old scheme, the serovar data (Table III) was changed to the new nomenclature via computer programming and tabulated together with the old one. 
Vol. 39, Suppl.
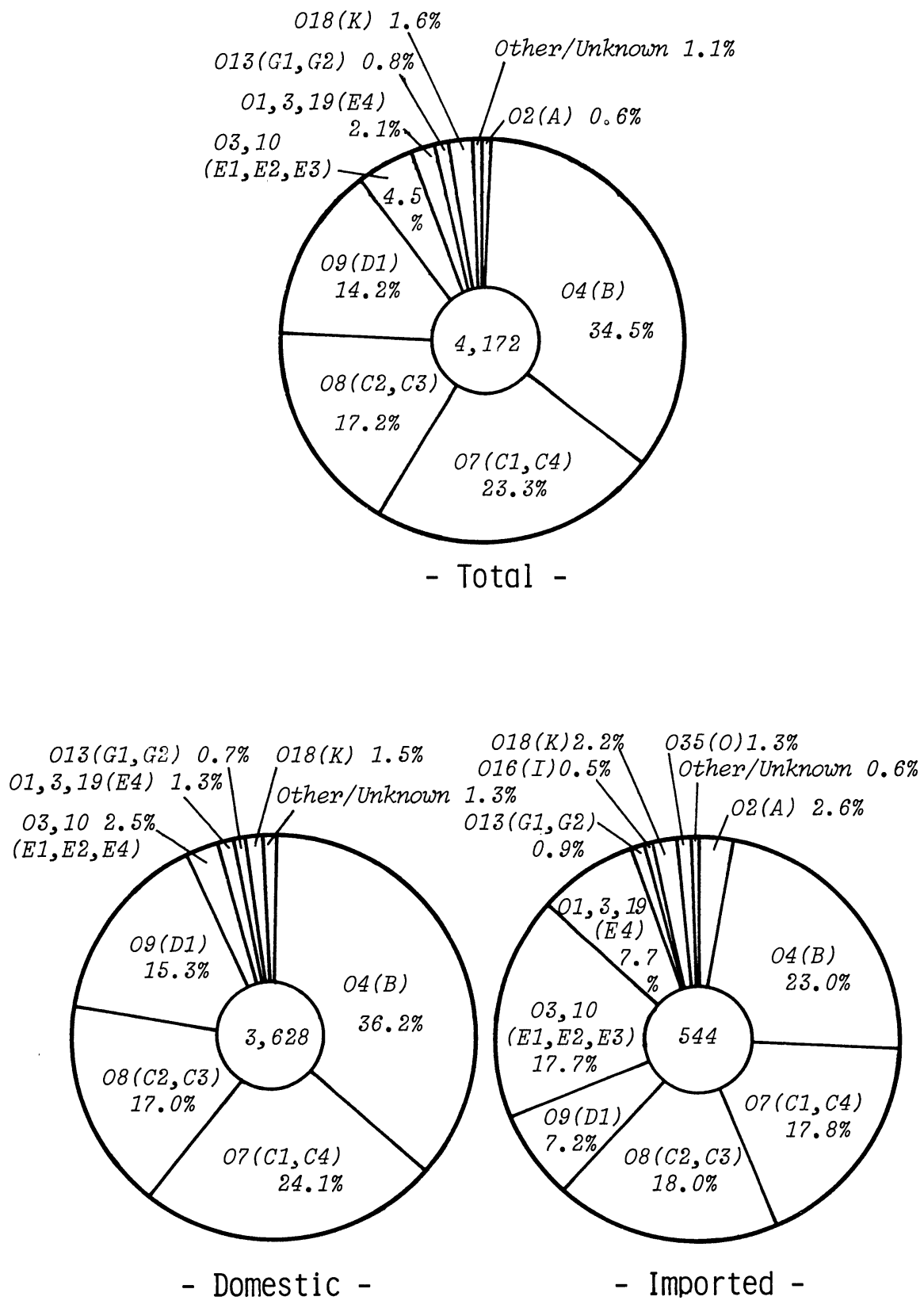

Fig. 8. Salmonella groups isolated by prefectural and municipal public health institutes and health centers, 1985

8-1. Isolations from humans 


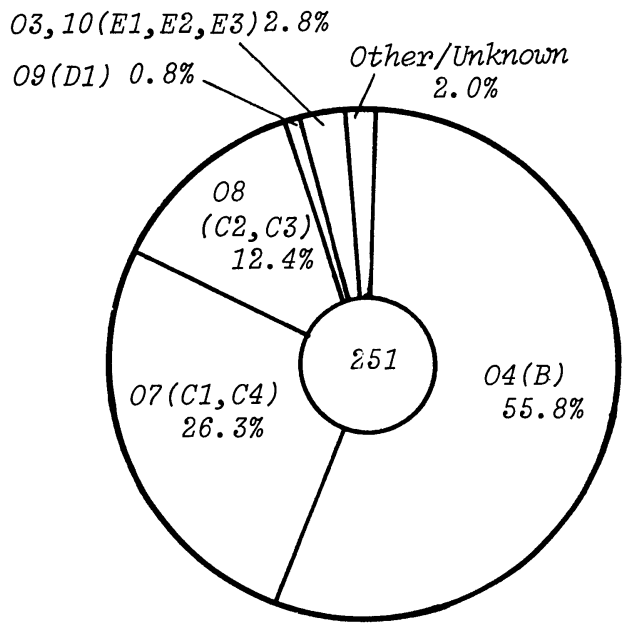

- Food -

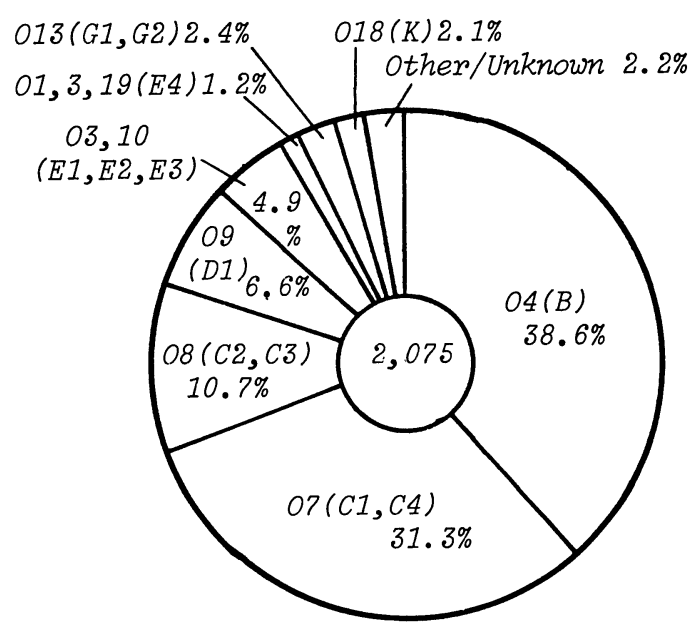

- Environment -

8-2. Isolations from food and environment

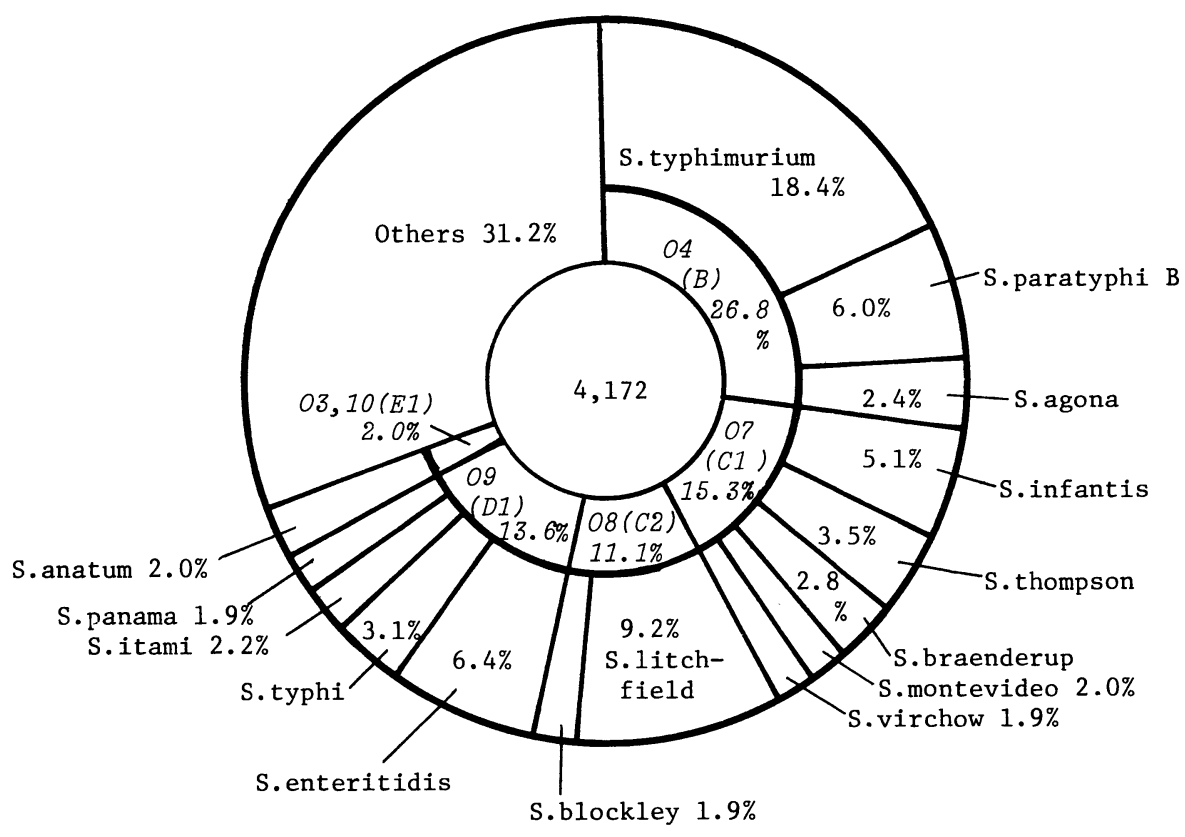

8-3. Fifteen most common Salmonella serovars from humans 
Vol. 39, Suppl.

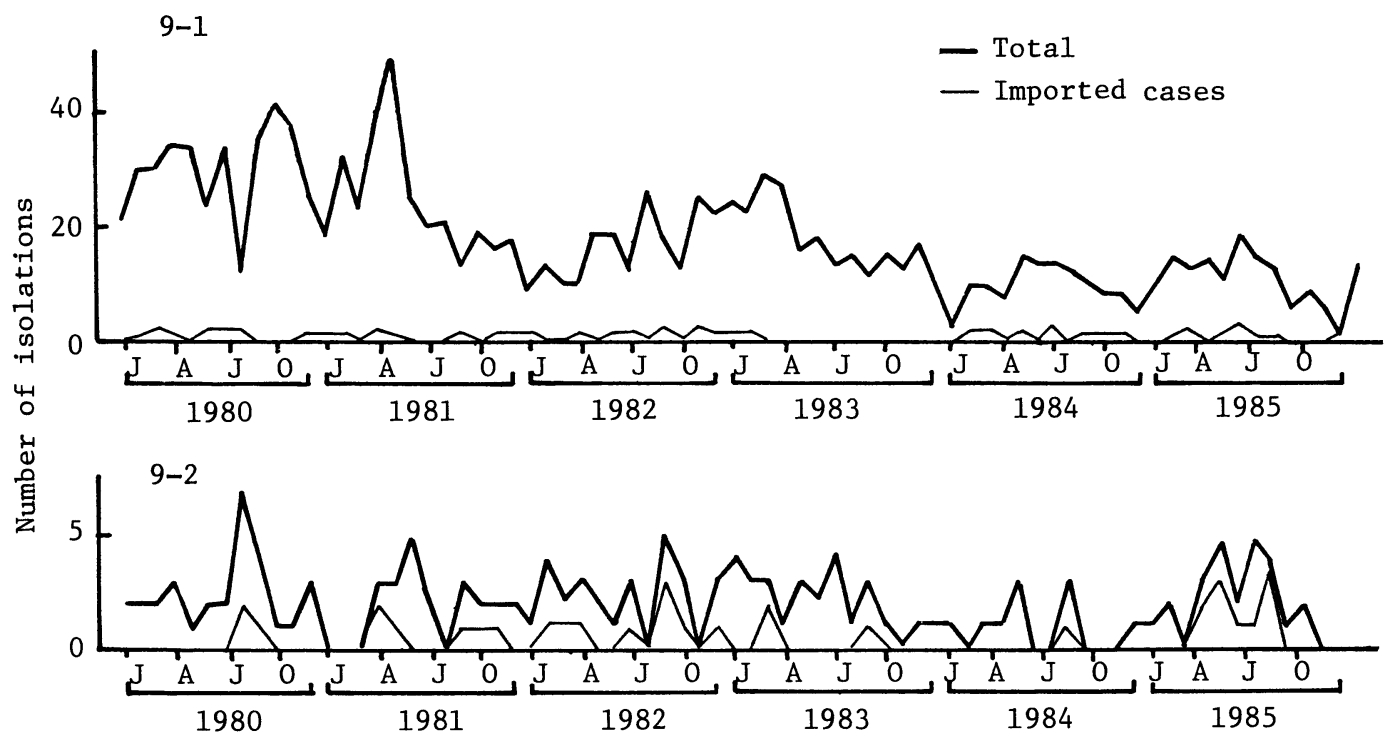

Fig. 9. Reported isolations of S. typhi and S. paratyphi A from humans by prefectural and municipal public health institutes and health centers, by month, $1980-1985$

9-1. Isolations of $S$. typhi

9-2. Isolations of $S$. paratyphi A

\section{S. typhi, S. paratyphi A and S. paratyphi B}

Among Salmonella described above, reported findings of S. typhi totaled 132 isolations (10 imported cases) at $\mathrm{PHI} / \mathrm{HC}$. This accounted for $120 \%$ of last year's isolations. There were 25 isolations of $S$. paratyphi $A$ reported (14 imported) and 243 isolations of $S$. paratyphi $B$ (five imported) at PHI/HC. IDH reported: $58 S$. typhi (20 imported), $14 \mathrm{~S}$. paratyphi $A$ (10 imported), and $11 S$. paratyphi $B$ (one imported). No seasonal trends were detected for S. typhi or S. paratyphi A. However, isolations of $S$. paratyphi $B$ increased in the summer, as did many other Salmonella, and peaked in August (Fig. 9-1, 9-2).

Reports of $S$. typhi, and S. paratyphi $A$ and $B$, submitted in accordance with a notice from the Bureau of Public Health, represented the total number of cases of typhoid and paratyphoid fevers in Japan on a national scale. For patients and carriers in 1985, there were 248 cases of $S$. typhi (41 imported), 44 cases of S. paratyphi $A$ (27 imported) and 115 cases of $S$. paratyphi $B$ (one imported). For $S$. 
paratyphi $B$, which had been under the Communicable Disease Prevention Law, the Ministry of Health and Welfare decided to delete $S$. paratyphi $B$ infection as of 14 November, 1985, from the application of the Law. As a result, the number of $S$. paratyphi $B$ for 1985 in this report included isolations only from January to November.

Among these isolations those which were submitted for phage typing accounted for $92 \%$ of $S$. typhi, $98 \%$ of $S$. paratyphi $A$ and $93 \%$ of $S$. paratyphi B. For S. typhi, 23 phage types were isolated, of which types M1, D2, UVS1(Untypable Vi strains), E1 and D1 were reported frequently and ranged throughout the country. UVS1 phage type, which mainly came from overseas travelers in previous years, occurred frequently in domestic cases (70\%) in 1985. There were 14 phage types of S. typhi from overseas travelers. Among them, four phage types, E2, O, T, 28, were not isolated from any domestic cases. For $S$. paratyphi $A$, five phage types were isolated. For $S$. paratyphi $B$, nine phage types were isolated and one isolation from an imported case was untypable.

Drug sensitivities were conducted on all the isolated strains submitted for phage typing. No resistant strain was found among them.

\section{Enteropathogenic $E$. coli}

In this surveillance system, $E$. coli isolation reports were limited to those considered as a cause of diarrhea. For PHI/HC in 1985, isolations numbered 1,569 showing a slight decrease in comparison with last year's 1,766 cases. Imported cases accounted for 776 cases (49.5\%); that is about the same number as last year. Enteropathogenic $E$. coli findings reported by $\mathrm{PHI} / \mathrm{HC}$, increased mainly in the summer reflecting outbreaks of food poisoning caused by this bacteria. In 1985, the peak incidence was from June to September (Fig. 10-1). However, the number of $E$. coli reports from GCI did not fluctuate and continued to maintain a relatively high level throughout the year (Fig. 10-2).

$1,569 \mathrm{E}$. coli isolations reported from $\mathrm{PHI} / \mathrm{HC}$ in 1985 were further tested. These were categorized by pathogenicity as follows; $2.0 \%$ enteroinvasive, $59.4 \%$ enterotoxigenic, and $32.0 \%$ enteropathogenic serotype. These frequencies were similar among the 776 imported cases at $\mathrm{PHI} / \mathrm{HC}$.

\section{V.parahaemolyticus}

In 1985, PHI/HC reported 2,929 isolations of $V$. parahaemolyticus, of which 339 were imported cases. The numbers accounted for $133 \%$ and $101 \%$ of last year's figures, respectively. Reports were concentrated in the summer with the peak in 
Vol. 39, Suppl.

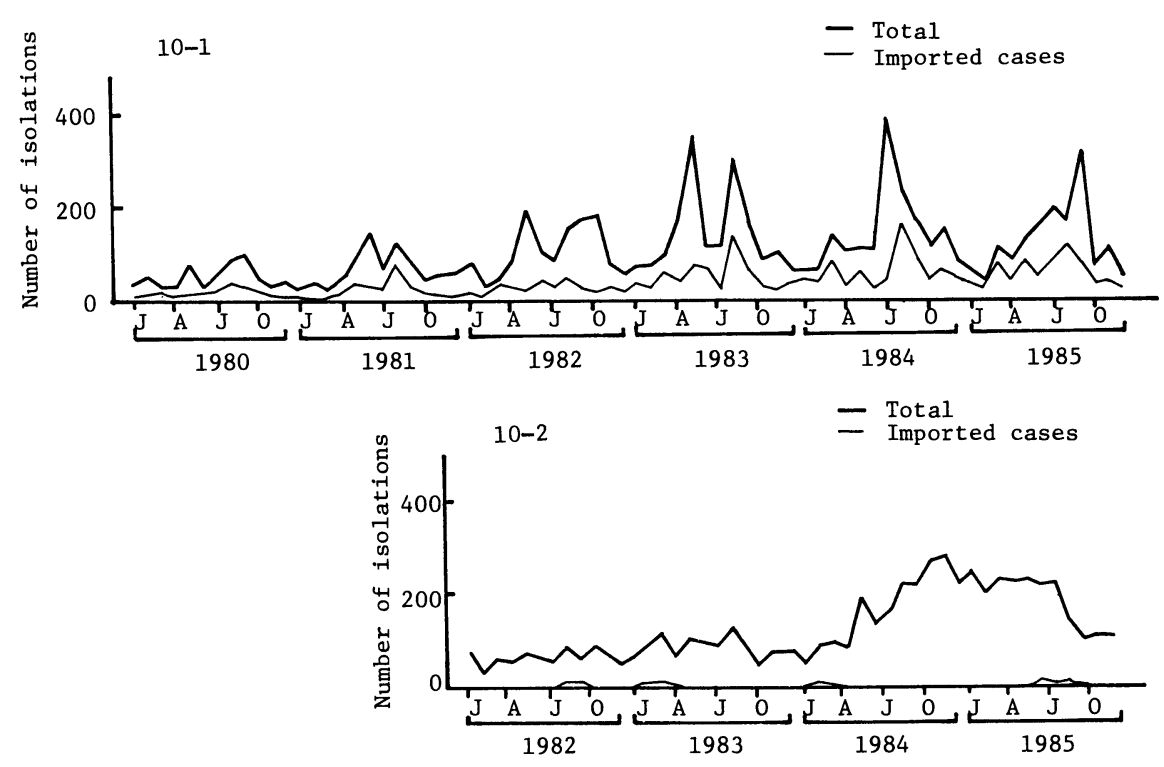

Fig. 10. Reported isolations of E. coli from humans, by month, 19801985

10-1. Isolations by prefectural and municipal public health institutes and health centers

10-2. Isolations by general clinical institutions

August-September, reflecting large-scale outbreaks of food poisoning caused by this bacteria (Fig. 11).

Isolations from IDH totaled 82 , with 21 imported cases. These figures represent $91 \%$ and $100 \%$, respectively, of the total reported in the previous year.

Reports from quarantine stations increased in 1985 up to 632 isolations (more than twice as many as last year's 293 isolations).

\section{C.jejuni/coli}

In this surveillance system, only findings of $C$. jejuni and $C$. coli which caused diarrhea were tabulated among Campylobacter isolations. The number of reports in 1985 was 2,810 (involving 127 imported cases) at $\mathrm{PHI} / \mathrm{HC}, 6,680$ (one imported) at GCI, and 131 (24 imported) at IDH, representing $117.1 \%, 124.3 \%$, and $89.7 \%$ of the number reported in 1984, respectively. Many outbreaks of enteritis by Campylobacter were caused by school lunch, and concentrated in the earlier part of the food poisoning season, from May to July (Fig. 12). 


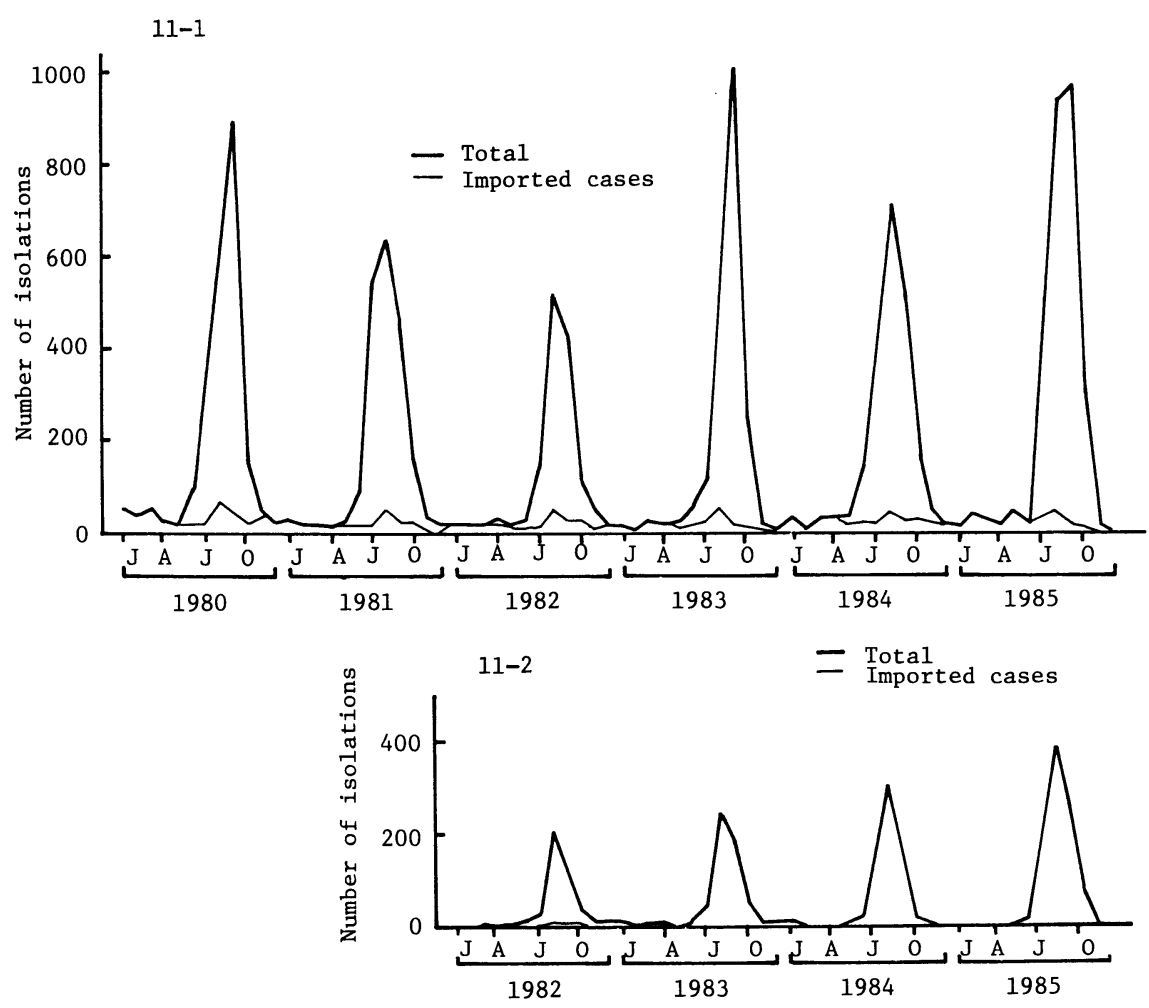

Fig. 11. Reported isolations of V. parahaemolyticus from humans, by month, 1980-1985

11-1. Isolations by prefectural and municipal public health institutes and health centers

11-2. Isolations by general clinical institutions

C. jejuni/coli were reported in considerably greater numbers at GCI than at $\mathrm{PHI} / \mathrm{HC}$, which is a characteristic of $C$. jejuni/coli different from the other intestinal bacteria. This is probably due to more frequent diagnostic assays performed in GCI; since the clinical symptoms of patients infected with this organism are relatively severe especially in the young child. Since considerable numbers of findings are reported not only in summer season but also in any other season by GCI, numerous sporadic cases occur all through the year. 
Vol. 39, Suppl.

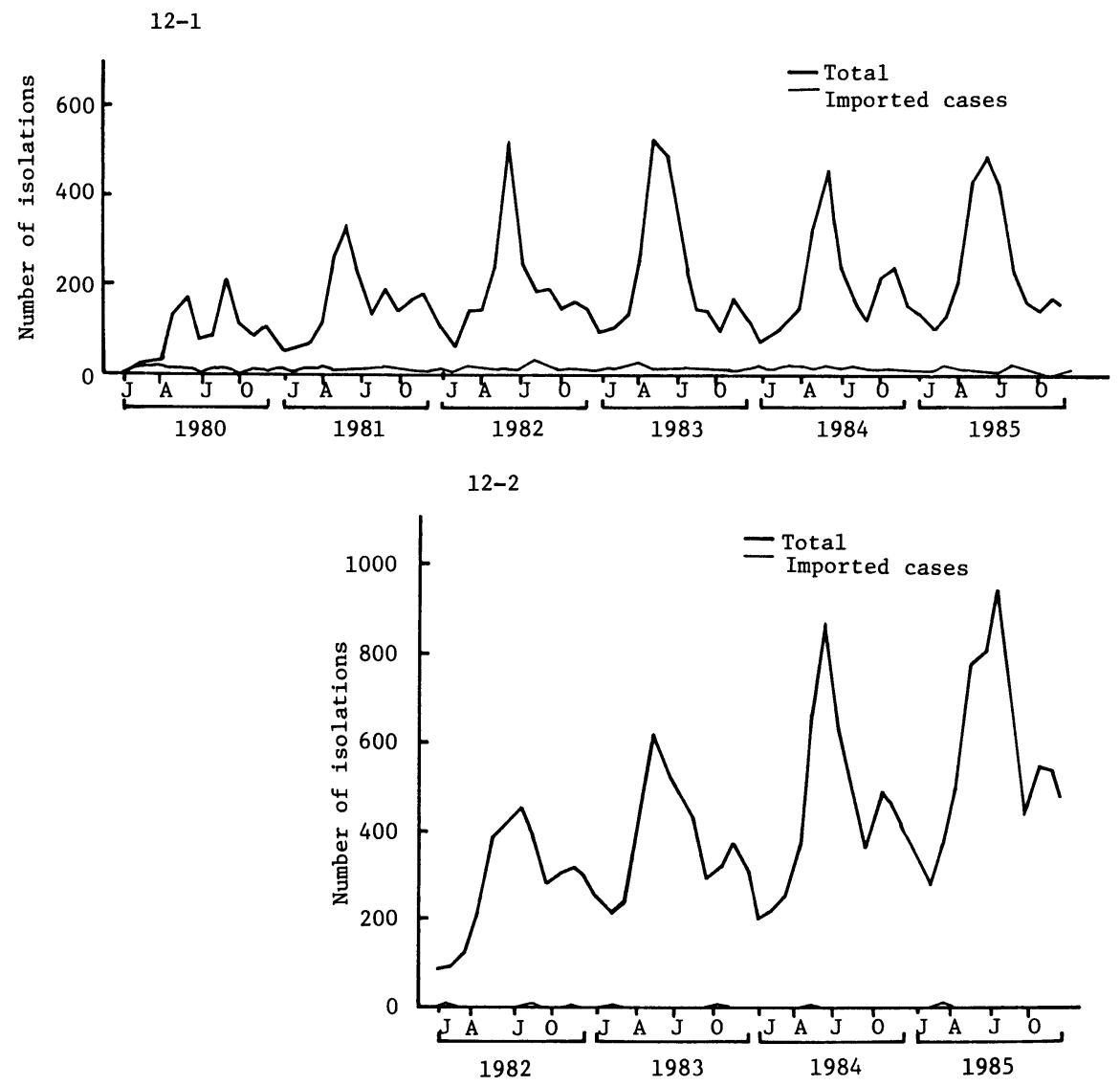

Fig. 12. Reported isolations of $C$. jejuni/coli from humans, by month, 1980-1985

12-1. Isolations by prefectural and municipal public health institutes and health centers

12-2. Isolations by general clinical institutions

\section{Other Bacteria Associated with Gastro-intestinal Diseases}

$V$. fluvialis, V. mimicus, Aeromonas hydrophila/sobria, and P. shigelloides were added to the report form in 1982 when these bacteria were considered as a cause of food poisoning. The legal notification was issued by the chief of the Section of Food Hygiene of the Ministry of Health and Welfare (Publication \#59 of 


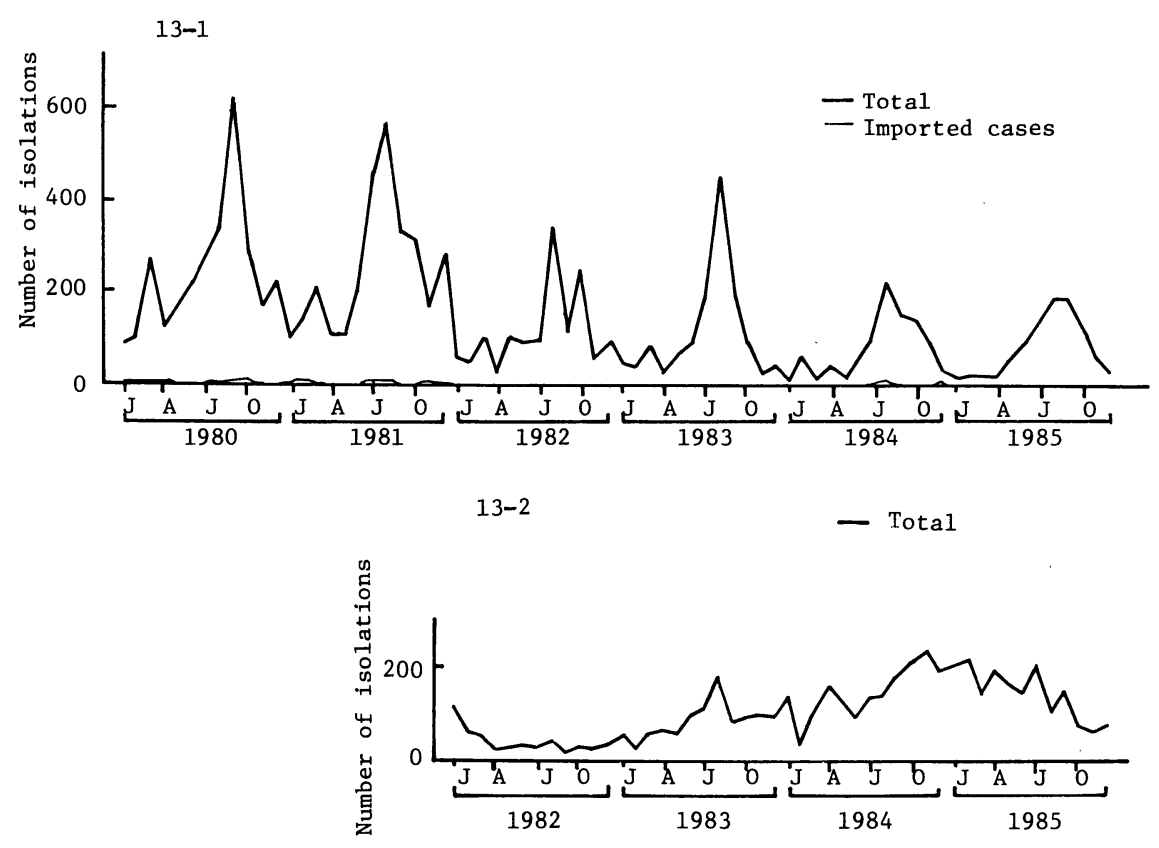

Fig. 13. Reported isolations of $S$. aureus from humans, by month, 19801985

13-1. Isolations by prefectural and municipal public health institutes and health centers

13-2. Isolations by general clinical institutions

Environment and Food: "For the handling of NAG Vibrio, Campylobacter and so on food hygiene" on 11th of March, in 1982). For these species, the isolations earlier than 1982 were reported as "Other bacteria". In 1985, the number of isolations at PHI/HC was: $44 \mathrm{~V}$. fluvialis (24 imported cases), $5 \mathrm{~V}$. mimicus (four imported), 134 A. hydrophila/sobria (14 imported), and $210 P$. shigelloides (179 imported). These numbers represented $80.0 \%, 35.7 \%, 161 \%$ and $150 \%$ respectively of the numbers reported in 1984. For $P$. shigelloides, the majority of the isolations were imported cases; $85.2 \%$ of total $P$. shigelloides in $\mathrm{PHI} / \mathrm{HC}$ were isolated from overseas travelers. Moreover, 477 isolations at quarantine stations represented $24.7 \%$ of the total number of findings reported from quarantine stations in 1985 (Fig. 14).

In 1985, reported number of isolations of Staphylococcus aureus (Fig. 13), Yersinia enterocolitica and Clostridium perfringens were 961 (none imported), 67 (31 imported) and 142 (none imported) from $\mathrm{PHI} / \mathrm{HC}$, respectively, and 1,754, 181 and four from GCI (none imported for these bacteria), respectively. 
Vol. 39, Suppl.

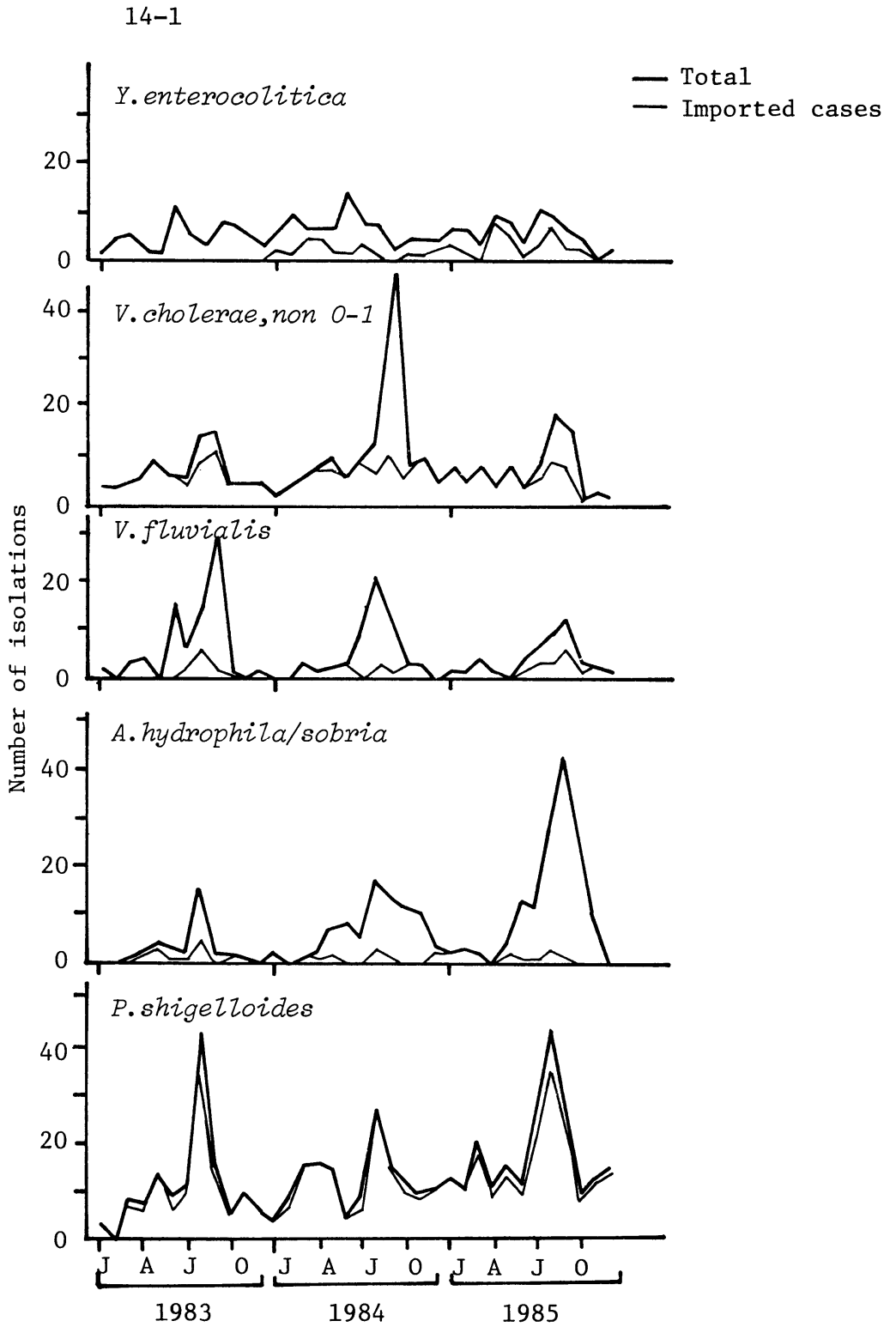

Fig. 14. Reported isolations of $Y$. enterocolitica, $V$. cholerae, non $0-1, V$. fluvialis, A. hydrophila/sobria and $P$. shigelloides from humans, by month, 1983-1985

14-1. Isolations by prefectural and municipal public health institutes and health centers 
Japan. J. Med. Sci. Biol., 1986

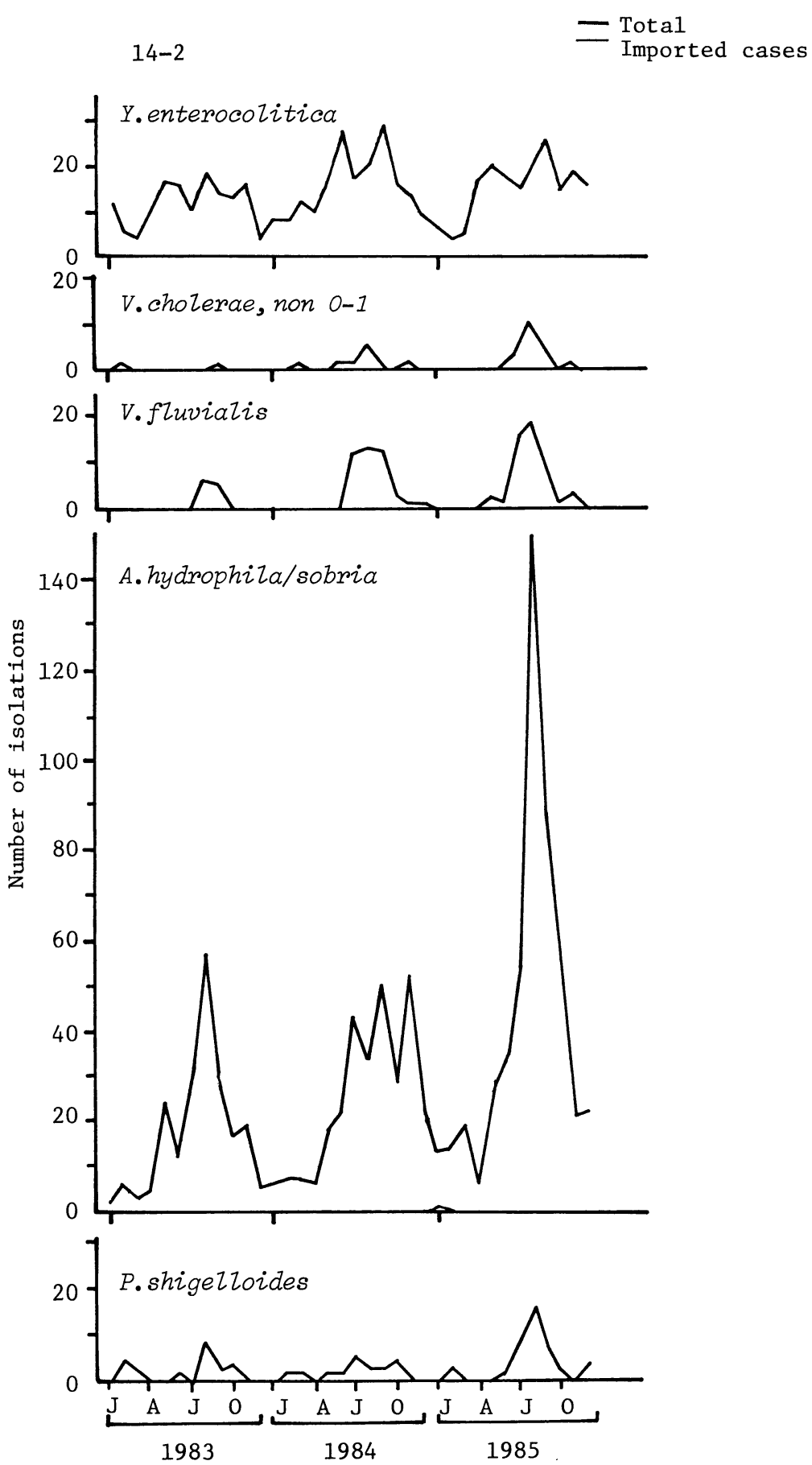

14-2. Isolations by general clinical institutions 
Vol. 39, Suppl.

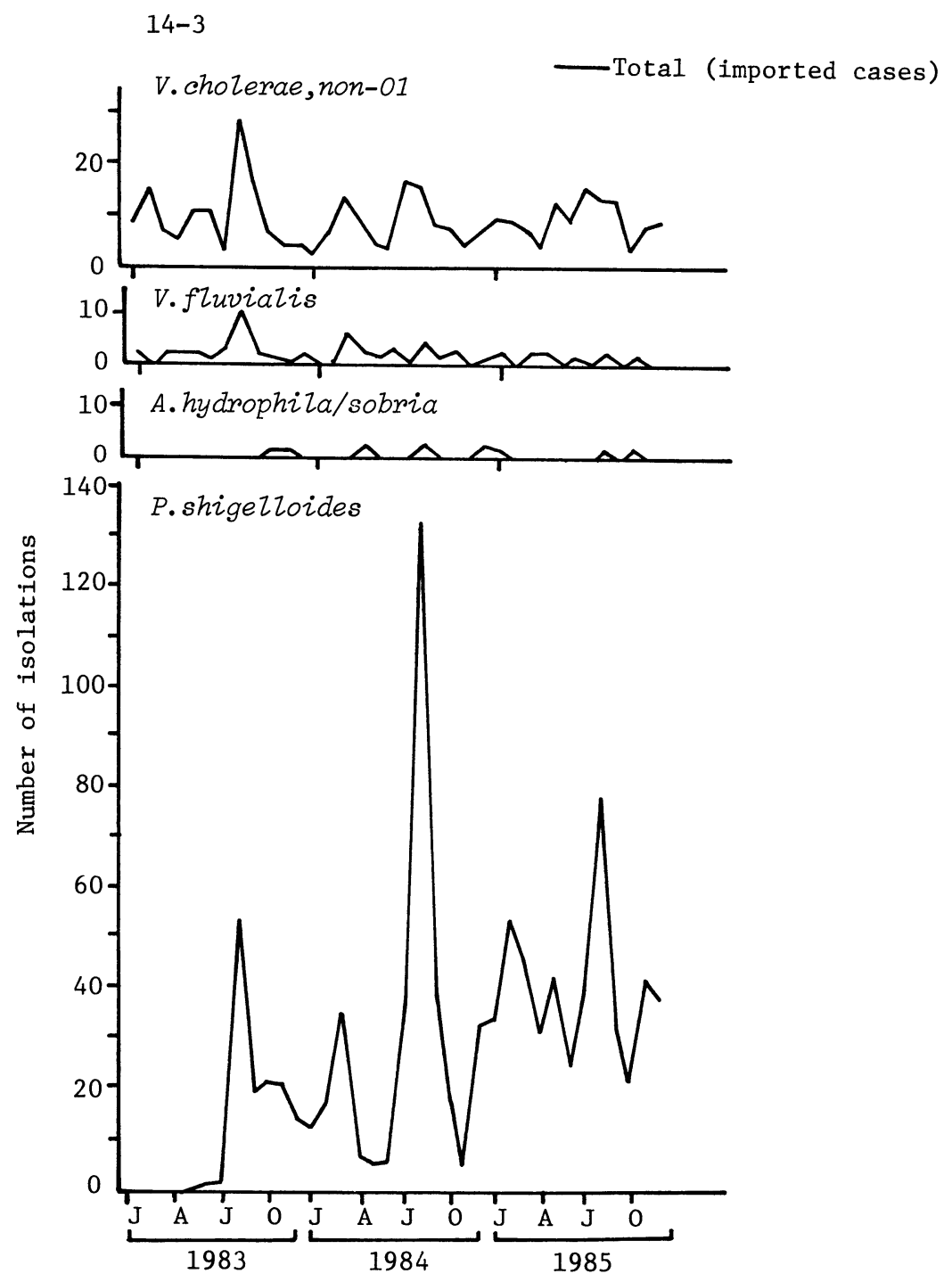

14-3. Isolations by quarantine stations

\section{Streptococcus}

In 1985, PHI/HC reported 3,359 isolations of Streptococcus, while GCI reported 18,426 isolations. The overwhelming majority of isolations in both reports were of group A, accounting for $80.1 \%$ at PHI/HC and $47.8 \%$ at GCI. 
Streptococcus $A$ was tested for type at public health institutes. Of the 2,671 strains tested for type, the order of frequency of findings were T-3 (28.9\%), T-12 (25.8\%), T4 (16.3\%), followed by a much smaller percentage of T-28, T-13, and T-1. Compared with the frequency of last year, the frequency of T-4 decreased and that of T-3 continued to increase. Peaks in January-March and November-December were seen for all types (Fig. 15).

\section{Neiserria gonorrhoeae}

In 1985, PHI/HC reported 686 isolations of $N$. gonorrhoeae (six imported), while GCI reported 1,722 isolation (no imported case). These numbers accounted for $88.4 \%$ (50\% for imported cases) and $120 \%$, respectively, of the number reported in 1984.

\section{Other Bacteria Associated with Respiratory Illness}

GCI submitted many reports of bacterial pathogens associated with respiratory illness, such as $K$. pneumoniae, $H$. influenzae and $S$. pneumoniae, of which detections in 1985 numbered 15,054, 17,110, and 9,391, respectively. Isolations of these three species increased and represented $111 \%, 113 \%$ and $103 \%$, respectively, of last year's figures. 
Vol. 39, Suppl.

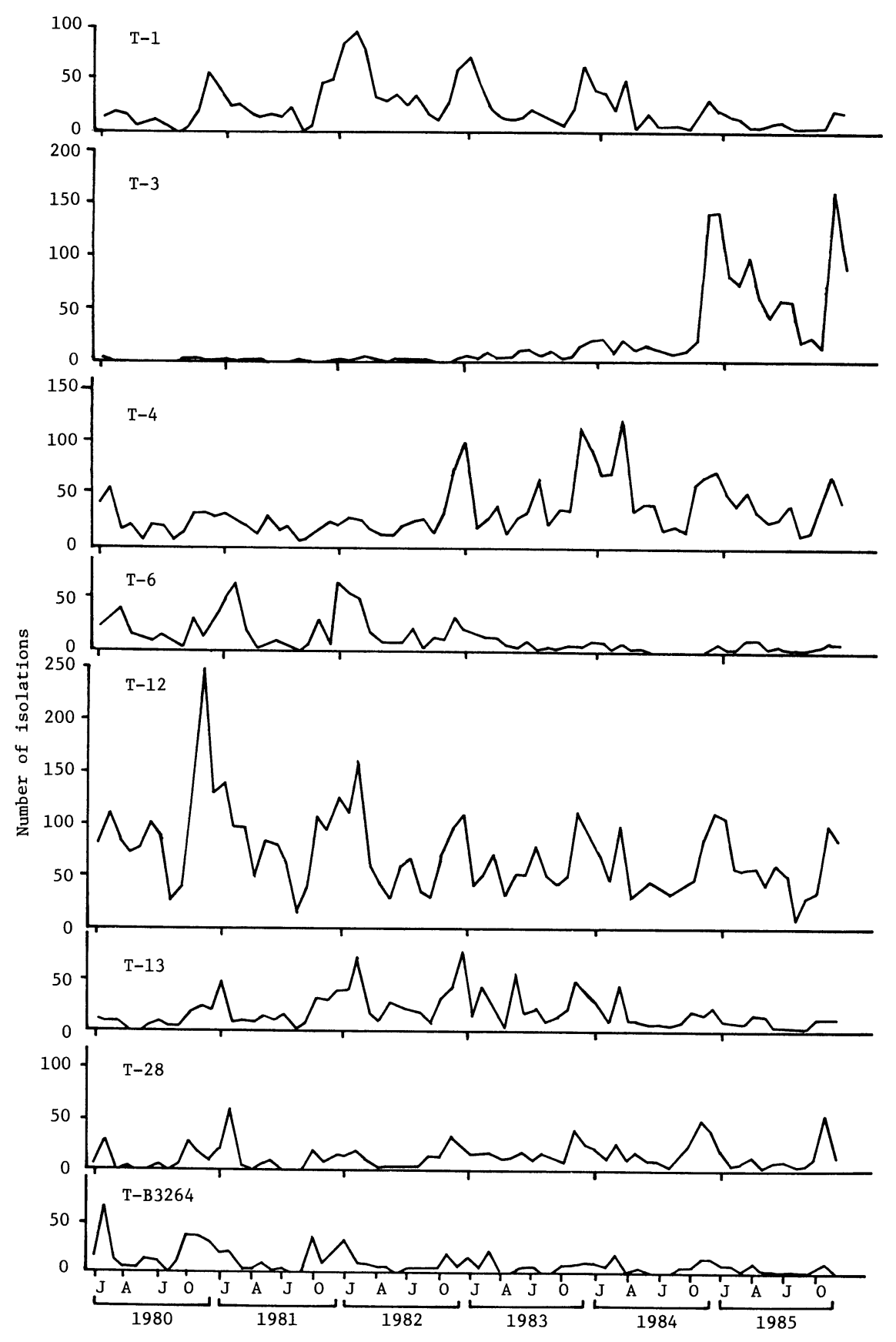

Fig. 15. Reported isolations of Group A Streptococcus serotypes from humans by prefectural and municipal public health institutes and health centers, by month, 1980-1985 